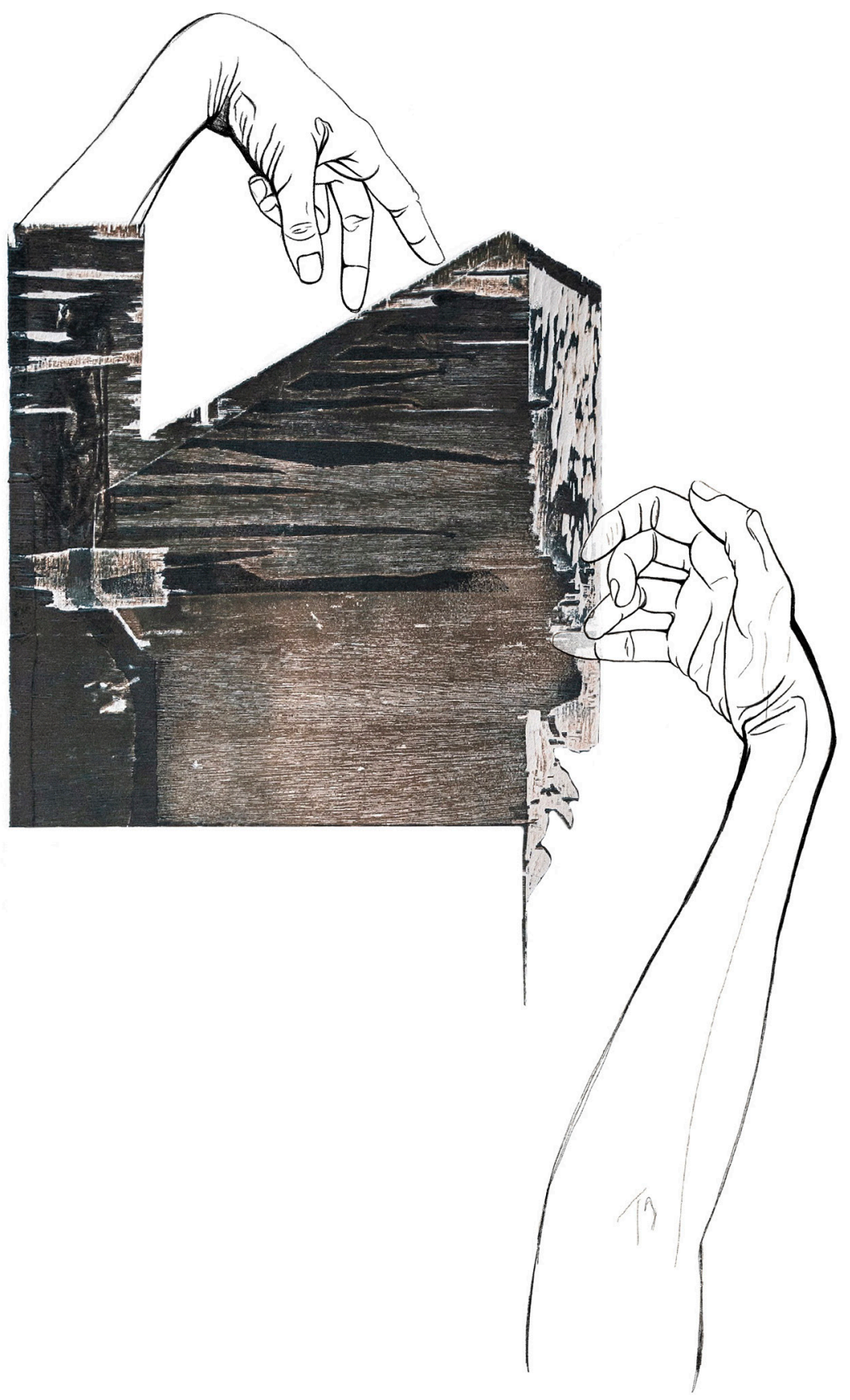


AUTORa: Olalla Cortizas 


\title{
Al aire de tu vuelo $(1941,1981)$, un libro manipulado por Celso Emilio Ferreiro
}

\author{
Xosé Manuel Dasilva \\ Universidade de Vigo \\ https://orcid.org/0000-0002-3360-6995 \\ [Recibido, 22 xullo 2020; aceptado, 30 setembro 2020]
}

[Dasilva, X.-M. (2020). Al aire de tu vuelo (1941, 1981), un libro manipulado por Celso

Emilio Ferreiro. Boletín Galego de Literatura, 57, "Estudos", 5-38]

DOl http://dx.doi.org/10.15304/bgl.57.7031

RESUMO Este artigo ten como obxectivo analizar as abundantes diferenzas entre as dúas edicións -unha de 1941 e outra de 1981- de Al aire de tu vuelo, primeiro libro publicado por Celso Emilio Ferreiro aínda despois da Guerra Civil. Sorprendentemente, nunca se reparou ata agora en tales diferenzas, a pesar de que son abondo evidentes e de considerable importancia. En efecto, advírtese por un lado que o número de poemas que forman parte das dúas edicións de Al aire de tu vuelo é distinto, debido a que se retirou unha cantidade significativa na segunda, dada a coñecer tras o falecemento do autor, se ben contou coa participación deste na súa preparación. Por outro lado, compróbase que as versións das composicións que permaneceron na obra ofrecen notables diverxencias en moitos casos.

Palabras Chave Poesía galega; Celso Emilio Ferreiro; Falange Española; Al aire de tu vuelo; reescritura intralingüística; autotradución recreadora.

ABSTRACT This article aims to analyze the abundant differences between the two editions -one from 1941 and another from 1981- of Al aire de tu vuelo, the first book published by Celso Emilio Ferreiro even after the Civil War. Surprisingly, such differences have never been noticed until now, despite the fact that they are quite evident and of considerable importance. Indeed, it is noted, on the one hand, that the number of poems that are part of the two editions of $A$ l aire de tu vuelo is different, because a significant amount was withdrawn in the second, released after the death of the author, although he had his participation in their preparation. On the other hand, it is verified that the versions of the compositions that remained in the work offer notable divergences in many cases.

KEYWORDS Galician poetry; Celso Emilio Ferreiro; Falange Española; Al aire de tu vuelo; intralingual rewriting; recreating self-translation.

\section{Introdución}

Al aire de tu vuelo. Poemas (1938-1940) supón, no ano 1941, o primeiro libro de versos de Celso Emilio Ferreiro, daquela xa non unha persoa enteiramente nova. Escrito en castelán, algúns dos textos databan, conforme se 
anunciaba no subtítulo, do período da Guerra Civil, durante a cal o escritor estivera unha boa parte do tempo na retagarda nunha situación propicia para se dedicar, sen excesivos atrancos, á creación poética. Catro décadas despois, unha segunda edición de Al aire de tu vuelo vería a luz, sen o subtítulo da primeira edición, no volume 3 das obras completas promovidas pola editorial Akal.

A finalidade deste estudo cífrase en pór ao descuberto as enormes discordancias estruturais e textuais que se distinguen ao confrontar a primeira e a segunda edición de Al aire de tu vuelo, endexamais identificadas ata o momento, tratando de esclarecer ademais as súas posibles causas. Verdadeiramente, Celso Emilio Ferreiro retirou, por unha banda, moitos textos na segunda edición e, por outra banda, afanouse en introducir unha morea de variacións nos poemas conservados. Emporiso, non declarou en ningures que emprendera estas dúas manobras, ocultando así a metamorfose da obra.

Tras o noso exame, a conclusión máis sobranceira aséntase no feito de que Al aire de tu vuelo, desde unha perspectiva histórica, debe avaliarse tomando como base a primeira edición, posto que transloce a feitura xenuína da obra. Pola contra, a segunda edición representa un produto manipulado, máis que remodelado en sentido propio, en razón da ausencia de transparencia do autor ao non facer constar unha revisión tan exhaustiva.

\section{A primeira edición de $A l$ aire de tu vuelo (1941)}

A edición inaugural de Al aire de tu vuelo apareceu a finais de 1941 estampada por Gráficas Torres, imprenta pontevedresa propiedade da familia do falanxista Sabino Torres, onde anos máis tarde sairían os títulos da Colección Benito Soto. Tratábase da estrea editorial de Celso Emilio Ferreiro, con case trinta anos, aínda despois da Guerra Civil. É inescusable aclarar que aquilo que se chama Cartafol de poesía, distribuído antes de 1936, nunca fora un libro, malia o que a miúdo se pensa, por mor do seu formato peculiar, xa que se trata dunhas tapas de cartolina para gardar follas con entregas sucesivas de Xosé Velo e Celso Emilio Ferreiro. Moito menos aínda merece Cartafol de poesía a categoría de libro tendo en conta a mínima cantidade de poemas que chegou a posuír, unicamente un de cada autor. 
Os gastos da edición de Al aire de tu vuelo cubriunos na súa integridade o propio Celso Emilio Ferreiro, quen levaba uns meses en Pontevedra. Chegara desde Celanova para desempeñar un posto privilexiado na Fiscalía de Tasas, organismo creado había pouco ao que accedían laboralmente persoas afíns ao Réxime. Francisco Fernández del Riego (2003, p. 169), compañeiro de Celso Emilio Ferreiro na Federación de Mocedades Galeguistas, salientaría a súa "estrañeza ó saber que Ferreiro ocupaba en Pontevedra a secretaría da Fiscalía de Taxas”. Pola súa parte, Hipólito de Sá (1979), habitual nos ambientes locais, empregaría a fórmula "el otro Celso Emilio" no referente a este ciclo do poeta, "muy alejado de ese protagonismo político y revolucionario con que ahora se le quiere encumbrar".

Celso Emilio Ferreiro viviu en Pontevedra ata os últimos meses de 1950, altura en que se trasladou a Vigo para exercer como procurador dos tribunais, entre outras tarefas. A mediados do ano anterior, conseguira o nomeamento que o autorizaba a desempeñar esta profesión, outorgado polo Ministerio de Justicia, figurando no expediente de solicitude a súa condición de militante de Falange Española Tradicionalista y de las Juntas de Ofensiva Nacional Sindicalista y "adicto al Nuevo Estado" (Dasilva, 2016, pp. 70-71). Un irmán seu, José, tamén procurador, obtivera o título en 1932, se ben no seu caso mediante un exame na Audiencia da Coruña.

O título de Al aire de tu vuelo proviña dun verso ("al aire de tu vuelo, y fresco toma") de Cántico espiritual, de San Juan de la Cruz, e a futura esposa do escritor, Moraima, era a destinataria da dedicatoria. Como detalle importante, necesítase apuntar que non se rexistra que Celso Emilio Ferreiro solicitase o permiso preceptivo da censura franquista para $\mathrm{Al}$ aire de tu vuelo (Dasilva, 2012, p. 56), o máis seguro pola súa relación coas autoridades, derivada do seu quefacer profesional na Fiscalía de Tasas. Tampouco se documenta que pedise licenza, seis anos máis tarde, no relativo a Bailadas, cantigas e donaires, o seu libro seguinte. O exemplar de $\mathrm{Al}$ aire de tu vuelo que manexamos, dos fondos da Biblioteca do Museo de Pontevedra, ten esta nota autógrafa: "Al Sr. Filgueira Valverde, como homenaje a su gran inteligencia y muy cumplido saber".

O exemplo de Cándido Viñas Calvo, poeta local por antonomasia na capital pontevedresa por entón, quen adoitaba publicar persoalmente os seus libros, debeu de estimular a Celso Emilio Ferreiro para facer o mesmo. 
Sabino Torres (2014, p. 118), espectador do devir cotián do escritor naqueles anos, afirmou que gozaba de sobrados recursos económicos para asumir ese desembolso, polos emolumentos recibidos na Fiscalía de Tasas. Celso Emilio Ferreiro (1943) encargaríase precisamente de asinar unha recensión dun libro de Viñas Calvo, La cima extraviada, na revista Finisterre. Alén diso, non parece unha casualidade que o xornalista Bara (1941), desde El Pueblo Gallego, avanzase simultaneamente a inmediata saída de $A l$ aire de tu vuelo e doutro poemario de Viñas Calvo, titulado Valleamar.

Na nota informativa de Bara, comezábase invocando a figura do fundador de Falange Española, en alusión á caste dos dous poetas, se cadra polo ambiente en que se movían: "[...] siempre los pueblos, no contaminados de bestiales materialismos, se elevan, se ennoblecen, se mueven, como diría José Antonio, con esos espíritus superiores”. Na parte final, enlazando con esta aseveración, esgrimíase que Viñas Calvo e Celso Emilio Ferreiro "contribuyen a mover al pueblo, a elevar su espiritualidad, por lo que ya anticipadamente les expresamos nuestro parabién y la gratitud de todos". Outra particularidade do comentario de Bara era que dicía que o autor ourensán reunía no seu tomo "una selección de versos logradísimos, algunos ya dados a conocer en recitales diversos".

A primeira edición de $\mathrm{Al}$ aire de tu vuelo presentaba a suma de cincuenta poemas, os cales é posible dividir en tres grupos a partir do deseño editorial da obra. Inicialmente, asomaba un poema sen título e sen número, cuxo incipit é [Vengo], construído sobre o sintagma "al aire de tu vuelo" de San Juan de la Cruz. A continuación, sucedíanse trinta pezas sen título e numeradas correlativamente. Por último, atopábanse dezanove textos con título e sen numerar, baixo a epígrafe xeral "Poemas del ir y venir". Nesta derradeira sección, como lema, xurdían as seguintes palabras de Rabindranath Tagore: "Y nunca olvidaremos que es nuestra la amada de nuestros corazones".

Moito despois, Celso Emilio Ferreiro proclamaría nunha entrevista que o volume non entrañaba unha achega de feitío mimético, aínda que admitía o rastro dalgunhas voces significadas: "En $\mathrm{Al}$ aire de tu vuelo -poemas de un adolescente enamorado-, si hay algunas influencias, son de Juan Ramón Jiménez y de Lorca, maestros inevitables en aquella época" (Molina, 1979, p. 11). Á marxe da súa porción de orixinalidade sospeitosa, Al aire de tu vuelo non debeu de ter moita repercusión no seu tempo máis alá do círculo de 
amizades de Celso Emilio Ferreiro e dalgunhas tribunas falanxistas, polos materiais que se contabilizan acerca da súa recepción.

Alén da noticia xa glosada de Bara en El Pueblo Gallego, neste mesmo xornal localízase unha primeira recensión. Subscrita coas iniciais A. S. (1941), detrás das cales estaba con toda certeza o poeta e xornalista Ánxel Sevillano, púñase de relevo nas súas liñas o desequilibrio artístico dos textos, malia o aceptable nivel do libro: "Quizás, en algunos poemas, una manera desigual y un logro diverso, con valores poéticos desnivelados. Pero existen aciertos poéticos indudables". Con todo, o proveito principal deste comentario está en que deixaba patente a cativa sona de Celso Emilio Ferreiro como poeta por aquel entón:

Llega a nosotros el autor de este libro, editado sencilla y pulcramente. [...] ¿ Un primer libro de poemas? Ignoramos si existe el precedente, pero nos inclinamos a ver en este la prioridad. Un poco porque le encontramos el ímpetu, la frescura y la gracia de lo inicial, y mucho porque no se presenta con la aspiración de cosa acabada, sino que él mismo, implícitamente, se reconoce imperfecto, como en verdad lo es -forzosamente- todo lo humano.

Xesús Alonso Montero (1982, p. 51) informou de dúas recensións de $A l$ aire de tu vuelo, unha no diario Región, de Oviedo, firmada por Ramón GarcíaVela, amigo do poeta, en decembro de 1941 (R. G.-V., 1941), e outra no xornal portugués Maria da Fonte (Garibaldi, 1945), de Póvoa de Lanhoso, pequena localidade preto de fronteira con Galicia, bastante posterior. Esta última, curiosa pola data e por estar nun medio de comunicación foráneo, limitábase a dar unha benvida gabanciosa. Debido á súa singularidade, copiamos algúns anacos deseguido:

O poeta galego Sr. D. Celso Emilio Ferreiro enviou-me há tempos um exemplar do seu belo livro de poemas intitulado Al aire de tu vuelo.

Com uma magnífica apresentação gráfica, este livro encerra óptimos versos de nítido recorte clássico, que se lêem com enternecimento e encanto.

Celso Emilio Ferreiro escreve ao geito dos mestres, dá-nos por isso poesia pura, impregnada do mais belo e perfumoso lirismo. [...]

Trata-se de um livro de amor, amor cheio de candura e de suavidade.

Estamos em face de um poeta de altíssimos recursos -e incapaz de macular a ascese da sua poesia terníssima com impuros desejos. Gostei deste belo livro de Celso Emilio Ferreiro, a quem agradeço muito o exemplar enviado maila a dedicatória com que o enriqueceu. 
Á súa vez, García-Vela sinalaba marcas incontrovertibles de Juan Ramón Jiménez e Federico García Lorca en Al aire de tu vuelo, mais sen xulgar isto unha rémora:

Algunos de los poemas de Ferreiro dejan traslucir su influencia de la lírica juanramoniana (y hasta algún Lorca se ve también en cierto romance), de la que no puede desprenderse fácilmente. No voy a reprochárselo, porque su personalidad de auténtico poeta que conoce el lenguaje metafísico de las cosas, la adapta a su modo de sentir para cantar.

Máis adiante, incidía na evolución poética de Celso Emilio Ferreiro desde as ousadías do pretérito ao sosegado refuxio do clasicismo:

Es, desde luego, un romántico y hasta un místico. Y aquí está lo mejor. Celso Emilio Ferreiro; este Ferreiro, tan distinto del que conocí hace años, que parecía perderse entre los arrebatos frenéticos del vanguardismo, retorna a saciar su inquietud, de poeta auténtico, en nuestro pasado glorioso del Siglo de Oro. Y San Juan de la Cruz, y una preocupación por lo místico, se transluce ya en gran número de sus poemas (si exceptuamos algunos de cierto matiz realista), tampoco es un azar el título del libro.

Polas súas connotacións políticas flagrantes, unha recensión de Al aire de tu vuelo extremadamente valiosa, descoñecida ata hoxe, aparecía no rotativo falanxista La Nueva España, tamén de Oviedo (Sen sinatura, 1941). Dado que o libro era unha autoedición, o autor probablemente remitira un exemplar a este xornal. En tal recensión, tíñanse presentes as xornadas de Celso Emilio Ferreiro como soldado nas filas franquistas durante a defensa da capital asturiana, diante do asedio das tropas republicanas. Púñase énfase, en conexión con iso, na dimensión vivencial dalgunhas poesías:

Celso Emilio Ferreiro, el autor de este librito de versos, nos trae con él un recuerdo alegre y doloroso a la vez. El recuerdo de los días heroicos en que era Oviedo un ascua de entusiasmo en la defensa de la ciudad, hogar tan querido, tan íntimo y tan sugeridor de nostalgias en la ausencia. Estuvo Ferreiro aquí a nuestro lado peleando aquellos días terribles del asedio. Fue su pecho muralla en el sector de Santo Domingo, y ahora abre en nuestra memoria un amplio horizonte al pasado con el envío de estos poemas ligeros, alados, sutiles.

Canta Celso Emilio Ferreiro el recuerdo; pero no este recuerdo que su presencia espiritual despierta en nosotros. Ferreiro no es un poeta épico, sino un lírico de la más acendrada intimidad. [...]

Todos los poemas están compuestos en verso de lo que se ha llamado, atendiendo sólo a la medida silábica de arte menor, la mayor parte ajustados a una medida 
métrica normal; otros, en verso libre, en la medida y en la rima. Preferimos a los demás poemas los titulados con el verso inicial: "Estoy anclado", "Borrachos de vida nueva", "Había en el paisaje" y entre los que el autor llama "Poemas de ir y venir", el "Romance del regreso".

Outra recensión ignorada ata a actualidade, non menos elocuente politicamente, emerxía na revista Fotos. Semanario Gráfico de Información y Reportajes, editada durante a Guerra Civil en San Sebastián e despois en Madrid, cunha inequívoca orientación nacionalsindicalista (Sen sinatura, 1942). Era unha das publicacións semanais de Falange Española con máis resonancia, e incita ao asombro que se fixase en $\mathrm{Al}$ aire de tu vuelo axiña de saír do prelo, aínda que só ata certo punto. De acordo con Augusto Assía -ou sexa, Felipe Fernández Armesto-, Celso Emilio Ferreiro intentara, a finais de 1939, divulgar un poema na revista Vértice, tamén netamente falanxista (Gómez, 1989). O seu desexo non se vería cumprido porque os colaboradores da publicación adoitaban ser firmas acreditadas, e Celso Emilio Ferreiro naqueles tempos era un mero principiante.

Ao igual que no caso de La Nueva España, habería que conxecturar razoablemente que Celso Emilio Ferreiro mandara o libro a Fotos. Semanario Gráfico de Información y Reportajes. Esta era a nota sobre Al aire de tu vuelo, de signo non moi favorable, onde se puña o acento na visible inexperiencia e na escasa creatividade do poeta:

Vivimos años de gran fecundidad poética. Las musas se han vuelto prolíficas en extremo. Apenas sí se escriben otros libros de amenidad que no sean de versos. Y es forzoso confesar que, en el trienio que corre de 1939 a 1942, se han compuesto algunos libros excelentes de poemas. Este que ahora lanza al mundo Emilio Ferreiro está cantado en tono de confidencia. Por su factura responde a la moda poética de hace tres lustros; por su fondo, es más añejo: como que se inserta en los años de la producción lírica más subjetivizada de Juan Ramón Jiménez. Pero Ferreiro está aún poéticamente en sus comienzos. Es difícil profetizar, pero yo imagino que a la vuelta de más ejercicio y menos reflejos ajenos, Ferreiro logrará darnos frutos más perfectos. Hoy está en el titubeo de la primicia. Hay en él finura y limpidez de estilo, pero se echa de menos esa fuerza y ese ímpetu creador que indican al poeta hecho y derecho. Acaso el temario escogido por Ferreiro es un rosario de menudencias que determinan ya la falta de sentido hondo que se advierte en estos poemas. Y el caso es que zahorí de reminiscencias hallará en este libro acumulada mucha lectura. Pero poesía es creación. La lectura, si acaso, espolea y ofrece moldes; nunca determina el verso perdurable. 


\section{O proceso de xestación de $A l$ aire de tu vuelo (1938-1941)}

Segundo xa vimos, a edición primixenia de $A l$ aire de tu vuelo tiña como subtítulo Poemas (1938-1940), explicitándose dese xeito a etapa en que se escribiran as composicións. Algúns anos despois, o historiador literario Antonio Couceiro Freijomil (1952, p. 75), prestando atención fielmente a este pormenor, facíase eco no seu Diccionario bio-bibliográfico de escritores, na entrada pertencente a Celso Emilio Ferreiro, de que no libro se recollían "poemas correspondientes a su producción de 1938 a 1940".

Non se dispuña de ningunha clase de documentación, honestamente, que corroborase sen ningunha dúbida esta cronoloxía. Chegou ao público en datas recentes, non obstante, o volume Birimbao. Poemas de mí para ti (1937-1939) -designado así por decisión do seu responsable, o fillo máis pequeno do escritor-, con manuscritos e mecanoscritos de Celso Emilio Ferreiro durante a Guerra Civil, que pon en evidencia unha redacción primitiva dalgúns textos de $\mathrm{Al}$ aire de tu vuelo no transcurso da contenda (Ferreiro, 2020). É o que acontece cos poemas seguintes, para os que indicamos a súa referencia en Birimbao. Poemas de mí para ti (1937-1939) (Bir) e en Al aire de tu vuelo (AAV):

"Desnorteado" (Bir) - "Solo" (AAV)

"Regreso" (Bir) - "Romance del regreso" (AAV)

"Como si fuese un fuego" (Bir) - [Te darás generosa] (AAV)

"Presencia" (Bir) - [Estar contigo es estar sin ti] (AAV)

"Del mar al mar" (Bir) - "Del mar al mar" (AAV)

"Renunciación" (Bir) - [Estoy anclado] (AAV)

"Presagio de invierno" (Bir) - "Presagio" (AAV)

"Tençon d'amor para E. F. T." (Bir) - [¿่Se habrá borrado el sendero] (AAV)

"La novia de la adolescencia" (Bir) - [iQué lejos] (AAV)

"Invitación" (Bir) - [Ven al amor de mi noche larga] (AAV)

"Teléfono" (Bir) - [Cambiamos nuestras voces] (AAV)

En conxunto, ascenden a once textos de temática amorosa agás dous -"Desnorteado" e "Regreso"-, que evocan motivos ligados á Guerra Civil. Con respecto á súa época, sete ofrecen como data o ano 1938 -"Desnorteado", "Presencia", "Del mar al mar", "Renunciación”, "Presagio de invierno", 
"Tençon d'amor para E. F. T." e "La novia de la adolescencia"-, tres o ano 1939 -"Regreso", "Invitación” e "Teléfono"- e un carece de anotación temporal - "Como si fuese un fuego". Certamente, a localización destes textos na Guerra Civil ratifica que Celso Emilio Ferreiro tivo moito lecer como soldado para se consagrar ás musas, forxando preferentemente versos de asunto romántico.

Conforme se sabe, a Guerra Civil non constitúe un dos episodios da biografía de Celso Emilio Ferreiro do que se teña máis información. Esta pexa hai que lla apoñer nomeadamente a el mesmo, pois nunca se referiu a ese intervalo da súa traxectoria con diafanidade, case como se lle desconviñese. É algo que María Xosé Porteiro e José Antonio Perozo non pasaron por alto na súa extensa conversa co escritor, abrindo a porta a futuras indagacións:

Os que no vindoiro pescuden na vida e na obra de Celso terán que estudar de vagar xa que as testemuñas duns, as críticas dos outros e as verbas do autor misturadas con elas, crearon un certo confundimento ó redor de toda esta xeira vital de Ferreiro. As circunstancias guerreiras do poeta non están ben ás vistas. Nas nosas conversas, él decote se referirá ás consecuencias pasando por riba dos feitos e das anécdotas, como temos visto no denanterior apartado. (Porteiro e Perozo, 1981, p. 48)

Hoxe en día están nas nosas mans, afortunadamente, datos novos sobre este capítulo crucial grazas á exhumación de diversos documentos, algúns de natureza oficial (Dasilva, 2012; Dasilva, 2016). En síntese, cabe expor que Celso Emilio Ferreiro, con familiares estreitamente vencellados a Falange Española, como os seus irmáns Gumersindo e Polda, incorporouse sen moita demora ao exército franquista, formando parte en Oviedo do Regimiento de Infantería Milán número 32. A mediados de 1937, concedéuselle un longo permiso de catro meses que lle posibilitou desprazarse a Celanova. Previamente pedía, con carácter formal, unha "madrina de guerra" (Sen sinatura, 1937a).

De volta en terras asturianas, e logo de publicar no xornal El Compostelano un mes antes o poema "Prisioneros", afervoada apoloxía do bando sublevado, en decembro dese mesmo ano logrou un confortable destino na cidade ovetense adscrito á sección de Transmisiones de Asturias, onde estaría afastado das liñas de fogo ata o remate do conflito. O xornal falanxista La Nueva Espa$\tilde{n} a$, máis atrás amentado, daba conta, en outubro de 1937, do papel un pouco 
livián de Celso Emilio Ferreiro nun acto artístico do seu rexemento en honra da Sección Femenina:

En la tarde de ayer, los soldados del Regimiento de Milán obsequiaron a nuestras camaradas de la Sección Femenina con una velada en el Descanso del Soldado. [...]

El poeta gallego Ferreiro declamó admirablemente algunos poemas originales titulados: "Quietud", "Juaco", "Cita" y "Madre". Con fino humorismo advirtió a los oyentes que no se dejaran impresionar por la melancolía que translucían sus versos, porque era debido a una afección hepática que le aquejaba.

Como final interpretó la orquesta los himnos de la Legión, Falange, Requeté y concluyó con el himno nacional. (Sen sinatura, 1937b)

No volume Birimbao. Poemas de mí para ti (1937-1939) sobresaen algunhas cartas de Celso Emilio Ferreiro ao amigo celanovés Emilio Rodríguez, de alcume Prenta, que reflicten a súa experiencia pouca dramática como soldado. Nunha misiva do 7 de maio de 1938, relataba con vagar a vida apracible que levaba, onde mesmo había espazo para as andanzas amorosas:

Hace unos días le escribí a Remixio y de pasada le hablaba de aventuras en esta Asturias cachonda, aventuras feminoideas, naturalmente. Pues bien, [...] no ha encontrado mejor destino para mi carta que enseñársela a la hija de Don Antonio, ex alcalde y ex carabinero, a consecuencia de lo cual he recibido hoy mismo una carta con letra de pico, detonante y quejumbrosa, de alguien que si algún día significó algo para mí, fue precisamente porque yo estaba encadenado lamentablemente. (Ferreiro, 2020, p. 152)

É oportuno recalcar que os poemas con orixe en Birimbao. Poemas de mí para ti (1937-1939) non se transvasaron á primeira edición de $A l$ aire de tu vuelo sen máis. Ao contrario, sometéronse a unha reelaboración máis ou menos intensa segundo cada caso. En primeiro lugar, algúns textos mantiveron o título, pero nas máis das ocasións este cambiouse ou eliminouse. De calquera forma, de meirande trascendencia son as mudanzas que se observan dentro de cada poesía. Resulta excepcional que as modificacións non abunden, como pasa en "Desnorteado" e "Renunciación". Polo regular, as diverxencias entre as versións alcanzan unha magnitude que non pasa desapercibida, ata o punto de chegaren a ser algunhas veces máis ben substanciais.

Repárese, en calidade de expoñente, na versión do poema "Como si fuese un juego" que se acha en Birimbao. Poemas de mí para ti (1937-1939): 
Te darás generosa

en un abril completo.

Totalmente;

como el cielo al mar,

como la flor al viento.

Vendrás a mí en misa,

con los brazos abiertos.

Tu sombra en cruz,

temblando de mi deseo,

será una rapsodia

suave como un beso,

dado

en una madrugada

azul, plena de ensueños.

Juntos

iniciaremos un mismo vuelo,

como dos pájaros libres,

ebrios de rumbos nuevos.

Todo

sucederá sencillamente,

como si fuese un juego.

Será naturalmente

en un abril completo. (Ferreiro, 2020, p. 57)

$\mathrm{Na}$ primeira edición de $\mathrm{Al}$ aire de tu vuelo, onde perdeu o título, depara notorias alteracións como a supresión dalgúns versos ou a reformulación doutros:

Te darás generosa

en un abril completo.

Totalmente,

como el cielo a la mar,

como la rosa al viento.

Vendrás a mí, silenciosa,

con los brazos abiertos.

a crucificar tu sombra

en mi anhelo.

Juntos

emprenderemos el vuelo 
como dos pájaros libres

ebrios de rumbos nuevos.

Todo será sencillamente

como si fuese un juego.

Será -oh, dulce compañera-

en un abril perfecto. (Ferreiro, 1941, p. 23)

Un exemplo ostensible máis é a versión de "Teléfono" en Birimbao. Poemas de mí para ti (1937-1939):

Cambiamos nuestras voces

por el hilo secreto.

¿Quién eras, que me dabas

en tus ritmos abiertos,

lejanías azules

perdidas en el tiempo?

Tu voz se adelgazaba

como un hilillo tenso.

Y se hacía tan íntima

como el temblor de un rezo.

Y yo hundido en mí

como en un mar sin cielo

con el alma en los labios

salí a tu encuentro.

Eran noches heladas,

blancas de augurios plenos. (Ferreiro, 2020, p. 79)

Así entrou, igualmente sen título, na primeira edición de Al aire de tu vuelo:

Cambiamos nuestras voces

por el hilo secreto.

La tuya era delgada

como el temblor de un rezo.

Y yo hundido en mí

como en un mar sin cielo,

con el alma en los labios

iba alegre a tu encuentro.

Eran noches heladas, plenas de augurios tensos. (Ferreiro, 1941, p. 26) 


\section{A segunda edición de Al aire de tu vuelo (1981)}

Despois de corenta anos, $\mathrm{Al}$ aire de tu vuelo volvería chegar aos lectores a comezos da década dos 80 . Dentro do proxecto de obras completas alentado pola editorial Akal, integrábase no volume 3, logo de Cartafol de poesía e antes de Bailadas, cantigas y donaires. Os volumes 1 e 2 viran a luz en 1975. A denominación da obra estaba reformada claramente, ao prescindirse do subtítulo Poemas (1938-1940). Con iso borrábase calquera sinal sobre a data de creación dos textos, quizais para transmitir a idea de que naceran tras a conclusión da Guerra Civil.

A segunda edición de Al aire de tu vuelo tirábase do prelo logo do falecemento de Celso Emilio Ferreiro, mais este con antelación aludira expresamente á súa intervención no devandito volume 3:

En mis Obras completas no están eludidos ninguno de mis libros. Lo que ocurre es que saldrán en el tercer tomo, que se está preparando en estos momentos. Ello es debido a que la inclusión de mis obras fue organizada cronológicamente en orden inverso. (Molina, 1979, p. 11)

Alén do título, esta segunda edición de Al aire de tu vuelo presentaba outras novidades relevantes. A primeira tiña que ver coa cantidade de textos, trinta e un nada máis, no canto dos cincuenta da primeira edición. Sobreviviu o poema inicial sen título e sen número inspirado en San Juan de la Cruz, mais do grupo de dezanove pezas sen título e numeradas soamente se traspasaron vinte e unha, mentres que outra perdeu o número que lle cadraría -28- e recibiu o título "Canción de cuna". A epígrafe "Poemas del ir y venir" do apartado consecutivo tamén se relegou, pasando ademais a estar conformado este por nove textos con título e sen numerar en lugar de dezanove.

No cadro seguinte ha ser doado percibir as mutacións de índole estrutural que arroxa a comparación entre a primeira edición e a segunda edición de $\mathrm{Al}$ aire de tu vuelo:

\begin{tabular}{|c|c|}
\hline $\begin{array}{c}\text { Al aire de tu vuelo (1941) } \\
{[\text { Vengo] }} \\
{[<\text { "...al aire de tu vuelo", San Juan de la Cruz] }}\end{array}$ & Al aire de tu vuelo (1981) \\
\hline $\begin{array}{c}\text { [Vengo] } \\
{[<\text { poemas sen título e numerados }} \\
(1-30)\end{array}$ & $\begin{array}{c}21 \text { poemal aire de tu ven título e numerados (1-21) e } 1 \text { poema Juan de la Cruz] } \\
\text { con título e sen numerar ("Canción de cuna") }\end{array}$ \\
\hline "Poemas del ir y venir": 19 poemas con título e sen numerar & 8 poemas con título e sen numerar \\
\hline Número total: 50 & Número total: 31 \\
\hline
\end{tabular}


Ao final deste artigo, en anexo, transcribimos os dezanove poemas omitidos, coa numeración ou co título da primeira edición. Con relación a Cantigas, bailadas y donaires, o segundo libro de Celso Emilio Ferreiro, débese facer fincapé en que tamén nel se certifica que faltan textos ao cotexar a primeira edición de 1947 e a segunda edición no volume 3 das obras completas, mais en número moi inferior, xa que só afecta a dous, os titulados "Elegía" e "Viento del sur".

Após unha lectura atenta, o certo é que non semella sinxelo determinar unha razón exclusiva para fundamentar esta flutuación tan estimable, decidida por Celso Emilio Ferreiro, na cifra de poesías de Al aire de tu vuelo. Nalgúns casos, poderíase alegar a percepción por parte do autor, pasado o tempo, da pobre valía dos textos. Polo demais, no titulado "Del mar al mar" albíscase unha débeda esaxerada, ata rozar a imitación servil, coa estética de Manuel Antonio en De catro a catro. En canto a outros exemplos, como "Romance del regreso", "Amigo" e "Oración”, o que se aprecia é a concorrencia de motivacións ideolóxicas. Hai que lembrar a este particular que, nos días en que chegou ao público a primeira edición de Al aire de tu vuelo, Celso Emilio Ferreiro era un empregado ben colocado nunha instancia franquista nada neutra, como a Fiscalía de Tasas. Tras outros choutos polo medio, salta á vista o brinco espectacular protagonizado por Celso Emilio Ferreiro ata as posicións exhibidas canda a segunda edición de $\mathrm{Al}$ aire de tu vuelo.

Á parte dunha ampla redución do inventario de poemas, o contraste das dúas edicións de $A l$ aire de tu vuelo leva a verificar, naqueles que se salvagardaron, cambios de inferior ou superior entidade. Para unha caracterización taxonómica, é pertinente deslindar entre substitucións léxicas e o que cumpriría cualificar, consonte a nosa proposta terminolóxica, como reescritura intralinguiística. Tal concepto asígnase á nova elaboración dun texto por parte do autor sen mudar de lingua, xa que cando esta operación se executa entre dúas linguas convén falar mellor de autotradución recreadora (Dasilva, 2020).

É indispensable resaltar que a reescritura intralinguiistica e a autotradución recreadora se erixiron en dúas prácticas habituais ao longo da carreira de Celso Emilio Ferreiro, e tanto no xénero poético como no xénero narrativo. Sen afondar arestora nisto para non desviarnos da meta primordial deste traballo, o que chama a atención sobre todo é que, en galego ou en castelán, o escritor ourensán materializou en oportunidades frecuentes varias versións, feitas 
públicas ou non, do mesmo texto. Amais diso, verteu con xenerosa autonomía obras entre o galego e o castelán de forma bidireccional, isto é, indiscriminadamente dun idioma a outro.

Volvendo a Al aire de tu vuelo, un exemplo palpable, por un lado, de substitucións léxicas vese no poema inicial [Vengo]. Na primeira edición comparece desta maneira:

\author{
Vengo \\ con un lucero en la mano \\ por el senderito nuevo. \\ $[\ldots]$ \\ Todas las amantes mías \\ han muerto. (Ferreiro, 1941, p. 5)
}

Certas palabras remudáronse na segunda edición:

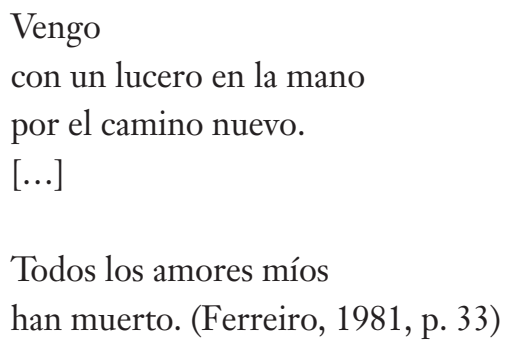

Algo similar ocorre con [Tú y yo bajo la noche]:

Tú y yo bajo la noche

somos dos islas sin nombre

$[\ldots]$

-Dame tu flor y tu agua, dame miel de tus palabras.

-No te las doy que las guardo para gozo de mi amado.

-iHazme a tu lado un hueco para dormir en silencio! (Ferreiro, 1941, p. 13) 
Velaquí o que se le na segunda edición:

Tú y yo sobre la playa

somos dos islas sin nombre

$[\ldots]$

-Dame tu flor y tu agua,

dame tu sed de palabras.

-No te las doy que las guardo

para llamar a mi amado.

-Hazme un lugar en tu lecho

para dormir en silencio. (Ferreiro, 1981, p. 40)

Entre outras moitas máis, unha última manifestación que se brinda é esta de [Había en el paisaje], poema que amosa ao principio a data "15 junio 1939”:

Había en el paisaje una quietud de siglos.

Bajo un cielo sin nubes

tú y yo recogidos

escuchando la eterna

melodía del río.

Mil cosas nos dijeron

tu corazón y el mío,

la brisa desde el árbol,

el pájaro en su trino. (Ferreiro, 1941, p. 33)

Alén da data, que se evaporou en congruencia coa desaparición do subtítulo Poemas (1938-1940), a fin de agachar calquera pista relativa á data das composicións, nalgún versos agroman outros termos:

Había en el paisaje

una quietud de siglos.

Bajo un cielo muy alto

tú y yo recogidos

escuchando la eterna

melodía del río.

Cuántas cosas dijeron

a tu anhelo y el mío, 
la brisa desde el árbol,

y el pájaro en su trino. (Ferreiro, 1981, p. 54)

No que atinxe á reescritura intralinguística en si, por outro lado, onde as emendas son máis profundas sen se circunscribir ao troco de palabras illadas, un modelo ben ilustrativo é [Amor, si yo te dijera]:

Amor, si yo te dijera

que por la boca del puerto

viene mi chalana nueva,

navegando por la ría

como una nube ligera.

Amor, si yo te dijera

que la mar es un espejo

y el mayo florido llega.

Amor, si tú me dijeras...

Entonces te llevaría

-ay amor-

en mi barca marinera. (Ferreiro, 1941, p. 6)

Con independencia doutras discrepancias leves, a poesía sufriu a poda de numerosos versos na segunda edición:

Amor, si yo te dijera

que en la isla de Toraya

tengo anclada mi gamela.

Amor, si yo te dijera

que la ría es un espejo

y el mayo florido llega.

Amor, si tú me dijeras... (Ferreiro, 1981, p. 34)

Non sen antes subliñarmos que os testemuños de reescritura intralingüística acadan unha proporción de veras extraordinaria, cómpre consignar que outra proba vizosa despunta en "Presagio":

Ya se presienten

los primeros acordes de la orquesta, 
las florecillas humildes

y una luna completa.

Ya rondan los mozos.

Todo tiene

una misteriosa transparencia.

¡Dios mío!

Este invierno interminable

¿tendrá algún día primavera?

La nieve

ignora las golondrinas

y la tibia brisa del sur

que nunca llega.

¡El bosque!

¡Los pájaros!

Pero ¿y mi tristeza? (Ferreiro, 1941, p. 52)

$\mathrm{Na}$ segunda edición, a factura dispar dalgunhas frases e a exclusión de moitos versos provocan que mesmo o sentido se transforme:

Ya se adivinan

los primeros acordes de la orquesta, las flores del camino

y la luna llena.

Todo tiene

una misteriosa transparencia.

Este invierno interminable, ¿tendrá algún día primavera?

La nieve ya no sabe que existen las golondrinas. (Ferreiro, 1981, p. 62)

Unha cuestión que suscita abraio é que non se detecta, en ningún lugar das obras completas de Celso Emilio Ferreiro en que se inseriu a segunda edición de $\mathrm{Al}$ aire de tu vuelo, nin o máis minúsculo apuntamento sobre o labor de refundición. A finais dos anos 70, o autor concibira un paratexto destinado a tales obras completas, baixo o pseudónimo Arístides Silveira, en que emprendía un percorrido retrospectivo a través do seu patrimonio literario. Alonso Montero valeuse deste escrito nunha monografía xa clásica sobre o poeta, onde se cita como "Notas a modo de limiar", especificando o seguinte: "Debería figurar, y no figura, como prólogo del volumen III de sus Obras completas (Akal, Madrid, 1981). Nos comunica el editor que se incorporará al 
volumen IV (y último). Desde ahora mencionamos este trabajo con las siglas NML" (Alonso Montero, 1982, p. 32).

Nunha contribución posterior do mesmo estudoso, dilucidábase a xénese do paratexto de Celso Emilio Ferreiro, aquí con outro nome: "Trátase de "Notas sobre os meus libros", redactadas pouco antes do seu pasamento. Ían saír no volume $4^{\circ}$ da Obra completa, que o editor nunca publicou. Contiña este volume: artigos, entrevistas, prólogos, poemas soltos, contos..." (Alonso Montero, 1989, p. 72). Inédito aínda polo momento, servímonos neste artigo dunha versión íntegra en galego depositada no arquivo de Alonso Montero que se custodia na Biblioteca da Deputación de Ourense, onde é accesible sen dificultades ao público.

En "Notas a modo de limiar", Celso Emilio Ferreiro expresábase con detemento verbo de Al aire de tu vuelo:

Polas mesmas razóns morais de porlle peito ó feito, o autor tampouco quere refugar este libro un tanto infantil de noivo deslumbrado polo amor e pola vida. (E tamén pola tristura, que soe ser compañeira inseparable dos outros dous deslumbramentos). Un libro de aprendiz de poeta, que escribe por primeira vez nunha lingua que non é a sua natural (xa que esta estaba entón vedada como instrumento literario) pretendendo seguir os ronseles trazados polos mestres que daquela lle puñan -como din na miña terra- o rabo ás cereixas da poesía castelán. Mestres que non é necesario citar, porque os seus nomes traslucen, aínda que de maneira torpe e desaliñada, ó longo das páxinas de $\mathrm{Al}$ aire de tu vuelo. Un libro intrascendente para calquera, menos pro autor que o escribiu e para a persoa a quen estaba dirixido. Son datos da pequena historia de cadaquén. Vivenzas cicais vulgares e cotianas, pero que trocaron para ben a vida dos protagonistas. Elo abonda.

Nesta demorada exposición, o primeiro aspecto que impacta radica na afirmación do escritor de que asumía Al aire de tu vuelo sen rexeitar nada. Non confesaba que desfigurara o libro en medida elevada, renunciando a poemas e transmutando os que resolvera preservar. Outro aspecto estraño reside en que manifestaba que botara man do castelán neste libro como ferramenta literaria por primeira vez. Non tiña en conta que antes de Guerra Civil xa escribira algunha composición nesta lingua, como a titulada "Romance del recuerdo", na revista Vida Gallega (Ferreiro, 1933), ou que sendo soldado na retagarda cultivara profusamente o mesmo idioma. Un terceiro aspecto desconcertante estriba en que invocaba, como pretexto para xustificar o uso do 
castelán, que o galego estaba proscrito no ámbito literario naquel momento. Non recordaba que Filgueira Valverde, a quen agasallara cun exemplar de Al aire de tu vuelo, publicara ese mesmo ano as súas "6 canciones de mar in modo antico" na revista Albor (Cuaderno de Poesía) (Filgueira Valverde, 1941), de Pamplona, ou que Ánxel Sevillano, comentarista do volume en El Pueblo Gallego, dera á luz O amor, o mar, o vento e outros gozos (Sevillano, 1938) en plena Guerra Civil.

A propósito do discurso de Celso Emilio Ferreiro sobre a confección das súas obras, faise imprescindible adoptar, en xeral, unha actitude en que prevaleza a cautela extrema, cando non a desconfianza. No que concirne a Antipoemas (Ferreiro, 1972), por traer a colación unha mostra concreta, xa quedou probado que a explicación fornecida con teimosía polo autor de que traducira o orixinal en galego para o castelán, unha vez refugado pola censura, co obxecto de concorrer ao premio franquista Álamo en 1972, non responde por enteiro á realidade (Dasilva, 2017). Concisamente, é ineludible precisar que a versión en castelán de Antipoemas só acolleu a metade das pezas do orixinal en galego, completándose con textos de Trece poemas iracundos y una canción inesperada (Ferreiro, 1970) e varios máis novos. Os poemas restantes do orixinal en galego de Antipoemas entrarían a forma parte, transfigurados nun grao sensible, dos títulos Cimenterio privado (Ferreiro, 1973), Onde o mundo se chama Celanova (Ferreiro, 1975a), Moraima: diario de a bordo (Ferreiro, 1975b) e O libro dos bomenaxes (Ferreiro, 1979).

\section{Conclusión}

Cando estaba en fase de preparación o volume 3 das obras completas, que acabaría abranguendo a segunda edición de $\mathrm{Al}$ aire de tu vuelo, Celso Emilio Ferreiro garantía que tanto este libro como Bailadas, cantigas y donaires se encontraban "hoy tan lejos de mi espiritualmente" (Molina, 1979, p. 11). Talvez suxestionado por esas palabras, Xosé Luís Méndez Ferrín opinaría categoricamente sobre o poeta celanovés, máis tarde, que "a poesía en español que publica nos anos corenta é unha poesía frívola, na que el non cría” (Álvarez, 2006, p. 47).

Para nós, a valoración rigorosa de $A l$ aire de tu vuelo non pode levarse a cabo desde esta óptica. A dicir verdade, Celso Emilio Ferreiro procedeu na 
segunda edición a rectificar a conciencia a primeira edición de 1941, o que non coincide co seu suposto desapego. Fíxoo ademais subrepticiamente, ao non comunicar semellante actuación de envergadura innegable. Por iso sostemos que, en última instancia, manipulou a obra, posto que desde o punto de vista diacrónico desvirtuou a súa esencia fidedigna. Non outra cousa implica desbotar un corenta por cento dos textos -19 de 50- e practicar substitucións léxicas, cando non consumar una reescritura minuciosa, na maioría dos demais.

Desde logo, debe considerarse que a versión autorizada de $\mathrm{Al}$ aire de tu vuelo é a que se subministra no volume 3 das obras completas, dado que foi a última que se proporcionou co visto e prace do autor. Agora ben, a lectura máis veraz é, ao noso xuízo, a que se desprende da primeira edición, cando Celso Emilio Ferreiro era un poeta incipiente cunha actividade profesional de perfil franquista. En definitiva, coidamos que unha aproximación comparativa á primeira e a segunda edición conduce a comprobar que o autor puido manipular Al aire de tu vuelo en beneficio persoal, coa intención de esvaecer con disimulo as pegadas incómodas do seu pasado.

\section{Referencias bibliográficas}

\section{Fontes primarias}

Ferreiro, C.-E. (10 de xullo de 1933). Romance del recuerdo. Vida Gallega, 562.

Ferreiro, C.-E. (1941). Al aire de tu vuelo. Poemas (1938-1940). Gráficas Torres.

Ferreiro, C.-E. (1970). Trece poemas iracundos y una canción inesperada. Expedien$t e, 2,20-26$.

Ferreiro, C.-E. (1972). Antipoemas. Delegación Nacional de Cultura. Colección Álamo.

Ferreiro, C.-E. (1973). Cimenterio privado. Edicións Roi Xordo. [Cun prólogo poema de Luis Felipe Vivanco e un epi(logo)tafio de Xosé Sesto.]

Ferreiro, C.-E. (1975a). Donde el mundo se llama Celanova / Onde o mundo chámase Celanova. Editora Nacional.

Ferreiro, C.-E. (1975b). Moraima: diario de a bordo. En Donde el mundo se llama Celanova / Onde o mundo chámase Celanova (pp. 123-175). Editora Nacional. 
Ferreiro, C.-E. (1979). O libro dos homenaxes. Akal.

Ferreiro, C.-E. (1981). Al aire de tu vuelo. En Obra completa 3 (pp. 31-63). Akal.

Ferreiro, C.-E. (2020). Birimbao. Poemas de mí para ti (1937-1939). Edicións Xerais de Galicia. [Edición crítica, introdución e notas de Xavier Ferreiro Loredo. Limiar de Ramón Nicolás.]

\section{Fontes secundarias}

A. [Ánxel] S. [Sevillano]. (11 de decembro de 1941). Al aire de tu vuelo, poemas de Celso Emilio Ferreiro. El Pueblo Gallego.

Alonso Montero, X. (1982). Celso Emilio Ferreiro. Ediciones Júcar.

Alonso Montero, X. (1989). Sobre a prehistoria de Longa noite de pedra. Boletín Galego de Literatura, 1, 71-95. http://hdl.handle.net/10347/1519

Álvarez, A. (2006). Entrevista a X. L. Méndez Ferrín: Celso Emilio é o grande poeta social e político da Galicia contemporánea. Arraianos, VI, 45-49.

Bara. (1 de novembro de 1941). Ante la próxima aparición de dos libros. El Pueblo Gallego.

Couceiro Freijomil, A. (1952). Ferreiro, Celso Emilio. Diccionario bio-bibliográfico de escritores, vol. II (p. 75). Editorial de los Bibliófilos Gallegos.

Dasilva, X.-M. (2012). A censura na obra de Celso Emilio Ferreiro. Grial, 195, 55-71.

Dasilva, X.-M. (2016). Arredor da homenaxe a Celso Emilio Ferreiro de 1966 (e outros episodios biográficos). Grial, 211, 55-73.

Dasilva, X.-M. (2017). Luz diáfana sobre Antipoemas, unha falsa autotradución de Celso Emilio Ferreiro. En A. Requeixo (Ed.), Sobre letras e signos. Estudos en homenaxe a Anxo Tarrío Varela (pp. 293-308). Xunta de Galicia.

Dasilva, X.-M. (2020). Eduardo Blanco Amor y la autotraducción recreadora: Os biosbardos / Las musarañas. Hikma, 19 (1), 239-264. https://doi.org/10.21071/ hikma.v19i1.12189

Fernández del Riego, F. (2003). Camiño andado. Editorial Galaxia.

Ferreiro, C.-E. (1943). Cándido Viñas Calvo, La cima extraviada, Pontevedra, Gráficas Torres, 1941. Finisterre, 1. 
Filgueira Valverde, X. (1941). 6 canciones de mar in modo antico. Albor (Cuaderno de Poesía), 7.

Garibaldi, A. (11 de marzo de 1945). Um livro de amor. Maria da Fonte.

Gómez, C. (21 de maio de 1989). Augusto Assía: Celso Emilio Ferreiro tenía una vocación poética que lo hacía incompatible con todos los sectarismos. La Voz de Galicia.

Molina, C.-A. (1979). El anverso literario y poético de Celso Emilio Ferreiro. Ínsula, $395,11$.

Porteiro, M.-J. e Perozo, J.-A. (1981). Celso Emilio Ferreiro. Compañeiro do vento e as estrelas. Akal.

R. [Ramón] G.-V. [García-Vela]. (14 de decembro de 1941). ¿Retroceso, retorno y superación? (Motivos sobre un libro de poemas). Región.

Sá, H. de. (2 de decembro de 1979). El otro Celso Emilio Ferreiro. Faro de Vigo.

Sen sinatura. (30 de marzo de 1937a). Solicitando madrinas de guerra. La Nueva España.

Sen sinatura. (13 de outubro de 1937b). En el Descanso del Soldado. Una velada de la Agrupación artística del Regimiento de Milán. La Nueva España.

Sen sinatura. (14 de decembro de 1941). Al aire de tu vuelo. La Nueva España.

Sen sinatura. (7 de febreiro de 1942). Al aire de tu vuelo. Poemas por Celso Emilio Ferreiro. Fotos. Revista Gráfica de Información y Reportajes, 258.

Sevillano, Á. (1938). O amor, o mar, o vento e outros gozos. Vigo.

Torres, S. (2014). Crónicas dun tempo escondido. Pontevedra 1930-1960. Editorial Galaxia. 
Poemas de $A l$ aire de tu vuelo (1941) eliminados en $A l$ aire de tu vuelo (1981)

11

Tu fuego encendido

en mi noche,

-dormida estrella,

rosa de alba-

tu fuego encendido,

es mi alma.

Sí.

Mi pobre alma huída

como un viento loco,

como una hoja seca,

como una idea vaga.

De pronto,

el viento encuentra el árbol,

la hoja el río,

la idea su palabra

28

y mi alma tu alma.

Dormida estrella,

rosa de alba. (Ferreiro, 1941, p. 17)

12

Lejos, lejos, mar adentro.

Walt Whitman

Tú y yo proas varadas

esperando plenitudes

para levar nuestras anclas.

La hora verde gritó,

"sí", en la noche clara

y temblando de frío

llegó el alba.

(Los anhelos dormidos

despertaron con alas)

Tú y yo: nuestros ojos, cuatro preguntas calladas, cuatro dudas encendidas, 
cuatro filos de navaja.

¿Qué nube, palmera o cielo

de nuestra isla soñada?

Tú y yo, el mismo sino.

Tú y yo, la misma playa.

Y el loco corazón niño

¿qué tierna canción cantaba?

Para las proas sedientas,

mar azul, rutas lejanas. (Ferreiro, 1941, pp. 18-19)

13

Vispera.

Un abril generoso

me floreció en las venas

Oh, la dicha de sentirse niño

y libre como una volvoreta.

Me falta, nada más, la sombra amada

de una alegre compañera:

un eco preciso y jubiloso

de esta bella primavera.

¡Oh, la dicha de sentir que todo

está vestido de fiesta! (Ferreiro, 1941, p. 20)

21

Un mundo para mí mismo,

-solo para mí- está hecho.

¿Y con quién sino contigo

voy rompiendo el secreto

de la estrella lejana

y el luminoso viento?

Y la razón secreta de las cosas,

en las cosas, como en un limpio espejo. (Ferreiro, 1941, p. 28)

\section{3}

Hay algo que me recuerda

el cielo infinito de tus ojos

y el grácil vuelo de tus manos. 
Es algo indefinible,

sutil y vago

como un perfume tuyo

en las cosas. Algo

como si, de pronto, me llamases

en el viento delgado,

en el camino,

en el árbol

en el río

y en el cantar del pájaro. (Ferreiro, 1041, p. 30)

27

Quiero mecer en mis brazos

tu lejano anhelo,

como si fuese, amada,

un pequeñuelo.

Tu lejano anhelo, amada,

dulcemente mecido,

como un pequeñuelo

dormido.

Como un pequeñuelo, amada,

tu anhelo lejano:

corazón al viento,

estrella en la mano.

Amada,

como un pequeñuelo.

En mis fuertes brazos

y en tu alto cielo. (Ferreiro, 1941, p. 34)

29

¡Qué tensión de anhelos!

¡Qué larga espera!

¿Cuándo vienes

paloma mensajera?

Por la curva infinita

-de azul y viento plena-

no vienes. Por la lejanía

de pinos, tampoco llegas.

¡Qué vacío en el alma,

paloma mensajera! (Ferreiro, 1941, p. 36) 
30

¿Se habrá borrado el sendero

que me llevaba hasta ella?

Jugando con su recuerdo

paso las noches en vela,

-ay amor-

paso las noches en vela.

¡Qué dolor si nuestras vidas

fuesen vidas paralelas,

que siempre caminan juntas

y nunca a juntarse llegan!

-ay amor-

y nunca a juntarse llegan.

Todo sería ceniza

y dolor de horas muertas.

En el vacío del alma

-ay amor-

sólo nostalgias y huellas.

Pero que mi voz se oiga,

que suene bien mi cadencia.

El compás de mi cantiga

es anhelo de tenerla,

y ser, fervorosamente,

mejor que luna, estrella,

y viento y río, mejor

que árbol y agua quieta,

-ay amor-

que árbol y agua quieta. (Ferreiro, 1941, pp. 37-38)

"Ideal"

Un Dios a quien rezar.

Un alma amiga.

Un libro manso.

Una cancón humilde y sentida.

Un amor infinito

para sentarse en la orilla.

¿Para qué más

en la vida? (Ferreiro, 1941, p. 41)

"Del mar al mar"

Atracaremos la dorna 
al este de la bahía.

Algas de todos los mares

engarzadas en la quilla.

El cafetín marinero

balandro quieto en la orilla.

Acordeones románticos,

sueños de humo en las pipas.

La hija del tabernero

curva rotunda en la brisa.

Singladuras esfumadas

adormecen las esquinas.

Las cartas de navegar

no reseñan nuestra isla.

Nos haremos a la mar

en la cruz de un medio día.

A babor de nuestras voces

rutas de anhelos perdidas.

S. O. S. de estrellas

cabalgan en la lejanía.

La proa de nuestra nave

32

arando va sus estrías.

El mar: cielo al revés.

El cielo: mar sin orillas. (Ferreiro, 1941, pp. 47-48)

"Romance del niño pobre"

... ese niño tiene en su

mano mi alma.

J. R. Jiménez

Su alma de niño bueno

torturada sin piedad.

Noches de insomnio cuajadas

de duda y miedo ancestral.

Sombras y luces flotando

como un barco sobre el mar.

Ay, su tristeza de niño.

Ay, el dolor de su hogar,

barquilla desmantelada

sin norte en su navegar.

¡Qué lejos están los ojos

de toda la humanidad! 
Blancas sonrisas de humo, ¡qué lejos del niño están!

Viento de abril trashumante, entrégale tu libertad. El niño está triste y solo, ay, qué solo y triste está.

La Sombra Vieja le sigue en su negra soledad.

Su alma de niño bueno navegando por el mar. (Ferreiro, 1941, pp. 50-51)

"Noche"

El viento en la media noche

¡qué bien imita a la abuela!

Uuh, uuh, uuuh!

Duérmete mi niña buena.

Anda la luna perdida ebria de frío y estrellas.

Agujas de hielo y lluvia

trenzan túnicas ingenuas.

Uuh, uuh, uuuh!

$\mathrm{El}$ viento por las callejas

peina faroles y esquinas

y arrulla los duermevela.

El viento en la media noche

¡qué bien imita a la abuela!

Insomnios de aliento turbio, espejo: laguna abierta, plata bruñida -gravitan sobre los sueños de piedra. En mi cerebro el taladro de una vaga sospecha, parece un grillo, mil grillos, que al aire su voz elevan.

El viento en la media noche mensaje azul de la abuela. (Ferreiro, 1941, pp. 53-54) 
"Sonnia"

Su nombre es bello y claro

como su mirada.

Sus trenzas son dos chorros

de miel en las espaldas.

Sonnia no sonríe.

Sonnia no habla.

Sonnia sueña teorías

de lentas caravanas, de anhelos imposibles

y de dulces nirvanas.

¿Quién le robó a Sonnia

su alma?

Sonnia no sonríe

pero cuando canta,

hay un rumor de humo,

hay un clamor de danzas,

de angelotes rubios

y negros con espadas.

Sonnia está ausente

de sí. ¡Está cansada!

¡Qué voces interiores,

qué secretas palabras,

escucha Sonnia cuando

entorna la mirada?

¿Qué tropel de ternura

se agolpa en su nostalgia?

Sonnia no sonríe.

Sonnia no habla. (Ferreiro, 1941, pp. 56-57)

"Sur"

¡Oh mi soñado sur

que nunca llegas!

Yo voy navegando,

sin timón ni estrella

tejiendo singladuras

y destejiendo esperas.

En la comba lejana

presagio las palmeras,

las guitarras dolientes, 
la eterna primavera.

Gozosa de futuros,

el alma por ti espera.

Besa tú, viento del sur,

las juveniles trenzas,

el puro torso erguido

de la novia primera.

Dame un rumbo exacto

-oh mi soñado sur

que nunca llegas-,

quiero incrustarme

en tu hondura negra. (Ferreiro, 1941, p. 58)

"Romance del regreso"

A mi madre.

Tejían cadencias puras

en vuelo las golondrinas.

Humo de voces y ritmos,

en la plazuela, las niñas.

Yo llegué sucio de niebla

por la vereda tranquila.

Tú estabas -serena y blanca-

en tu soledad metida

hilando copos de horas

y presencias presentidas.

-Mi madre: ya estoy de vuelta

de mis vagas lejanías.

Tú me contemplaste, toda

acurrucada en ti misma.

Había un temblor remoto

en la luz de tus pupilas.

Cuatro lágrimas fugaces

brillaron en tus mejillas.

Acariciaste mi frente

de duda y dolor henchida.

Me hablaste con tu voz dulce,

a un tiempo alta y sumisa:

-Estás ya de vueltas, hijo,

de tu larga correría...

-¿Qué hay más allá del monte?

-¿Qué hay fuera de esta vida 
plena de paz y de soles?

-Mi madre, solo hay heridas.

Afuera cantaba el sol

una canción blanca y tibia

$y$ un humo de voces tiernas

la brisa azul diluida.

Detrás de mí, ya cansados,

los sueños locos dormían.

-Mi madre: ya estoy de vuelta

de mis vagas lejanías. (Ferreiro, 1941, pp. 59-60)

"Amigo"

Aunque tú no me conozcas,

yo te conozco muy bien.

J. Krishnamurti

Rasga

los papeles viejos

36

de tus recuerdos.

Olvida si vas

o vienes.

Ya verás, amigo,

qué descanso,

qué blando descanso tienes. (Ferreiro, 1941, p. 61)

"Sombra"

Tenía sueños dormidos

en los párpados,

flores de sonrisas

en los labios,

tacto de lejanías

en las manos.

Pero le faltaba

eso que tienen los pájaros:

voluntad de horizontes,

ritmo, alas, espacio.

Negra sombra

que vas siguiendo mis pasos, 
¡cómo envidia tu suerte

la sombra quieta del álamo! (Ferreiro, 1941, p. 62)

"Ciudad"

Con las fauces abiertas

se acerca el alba.

Tinta negra vertida

la sombra de la estatua.

$\mathrm{Y}$ yo voy con mi niño,

niño: mi pena larga,

mi mundo presentido,

mi soledad elástica,

mi silencio mojado

en las estrellas altas.

La ciudad recupera

la silueta en el agua.

Pájaros dormidos

por el cielo pasan.

La torre y el río

sus saudades cantan.

Sol: cocodrilo rubio,

¡ya se ha muerto el alba!

$\mathrm{Y}$ yo voy con mi pena

larga, larga, larga... (Ferreiro, 1941, p. 63)

"Oración"

Yo, que soy la eterna luz,

be venido al mundo para

que quien crea en Míno

permanezca en tinieblas.

San Juan, XII, 46

Señor:

Tú que has roto el silencio

de mi noche lejana,

dame un límite, hazme

como el agua mansa.

De mis ritmos humanos

sé Tú batuta mágica.

Llena de Tu miel mi boca,

dame tus madrugadas 
y, como si fuesen Ángeles,

ponle a mis sueños alas.

Señor:

Que tus manos blancas

sean palomas de fe

en mis horas largas,

negras con Tu ausencia,

áridas.

Derrama sobre mí

Tu gracia.

Que mi nave sin rumbo

en Ti quede varada.

Señor:

Sobre mis campos yermos

deja caer la blanda

lluvia de Tu verbo

sin mácula. (Ferreiro, 1941, pp. 64-65) 